14 Adelson L. Slaughter of the innocents: study of forty six homicides in which the victims were children. $N$ Engl Med 1961; 264: 1345-9.

15 Sachs B, Hall LA. Maladaptive mother-child relationships: a pilot study. Public Health Nurs 1991; 8: 226-33.
16 Zuravin SJ. Severity of maternal depression and three types of mother to child aggression. Am $\mathcal{F}$ Orthopsychiatry 1989 59: 377-89.

17 Bourget D, Labelle A. Homicide, infanticide and filicide. Psychiatr Clin North Am 1992; 15: 661-73.

\title{
Transient hyperglycaemia
}

Paediatricians will be familiar with the phenomenon of transient hyperglycaemia in children with acute illnesses, especially episodes of asthma. Usually it is thought of as a physiological reaction to stress and no investigation or follow up is arranged but there have been suggestions that a significant proportion of these children might develop diabetes. How great is this risk? Should children with transient hyperglycaemia be investigated further, and if so, how?

Work at the Joslin Diabetes Center in Boston, Massachusetts, is reported in the fournal of Pediatrics (Raymonde HerskowitzDumont and colleagues, 1993; 123: 347-54). Sixty three children were studied and seven $(11 \%)$ of them developed diabetes within one to 18 months of the episode of transient hyperglycaemia but diabetes was much more likely to develop after transient hyperglycaemia found on routine checking of a well child (six of 19, 32\%) than after an episode of hyperglycaemia during an acute illness (one of 44, 2.3\%). Transient hyperglycaemia was found in $0.46 \%$ of nearly 64 thousand children seen either on the wards or in the emergency department of the Boston Children's Hospital.

Two immunological markers and two measures derived from an intravenous glucose tolerance test were found to predict the development of diabetes. These were: islet cell antibodies, insulin autoantibodies, stimulated insulin release, and rate of glucose disposal ( $\mathrm{K}$ rate). All of these tests had a positive predictive value of $100 \%$ for the development of diabetes. Negative predictive values were $96,98,98$, and $94 \%$ respectively.

Children who are found to have transient hyperglycaemia during an acute illness have a low risk of diabetes over the next year or two but those whose hyperglycaemia is unprovoked may have a risk of $30 \%$ or more. Available investigations detect those who will develop diabetes with a high degree of accuracy. The authors imply that investigations could usually be confined to the high risk group. 